\title{
Supplementary material for paper
}

\section{High-ozone Layers in the Middle and Upper Troposphere above Central Europe: Potential Import from the Stratosphere along the Subtropical Jet Stream}

Thomas Trickl ${ }^{1}$, Nathalie Bärtsch-Ritter ${ }^{2}$, Holger Eisele ${ }^{1}$, Markus Furger ${ }^{2}$, Robert Mücke ${ }^{1}$, Michael Sprenger ${ }^{3}$ and Andreas Stohl ${ }^{4,5}$

${ }^{1}$ Karlsruher Institut für Technologie, Institut für Meteorologie und Klimaforschung (IMK-IFU), Kreuzeckbahnstr. 19, D-82467 Garmisch-Partenkirchen, Germany

${ }^{2}$ Paul Scherrer Institut, Labor für Atmosphärenchemie, CH-5232 Villigen PSI, Switzerland

${ }^{3}$ Eidgenössische Technische Hochschule (ETH) Zürich, Institut für Atmosphäre und Klima, Universitätstraße 16, 8092 Zürich, Switzerland

${ }^{4}$ Lehrstuhl für Ökoklimatologie, Technische Universität München, Am Hochanger 13, D-85354 Freising-Weihenstephan, Germany

${ }^{5}$ New address: Norwegian Institute for Air Research, P.O. Box 100, Instituttveien 18, N-2027 Kjeller, Norway

Time Series for Case 1 (31 May 1996, Sec. 3.1)

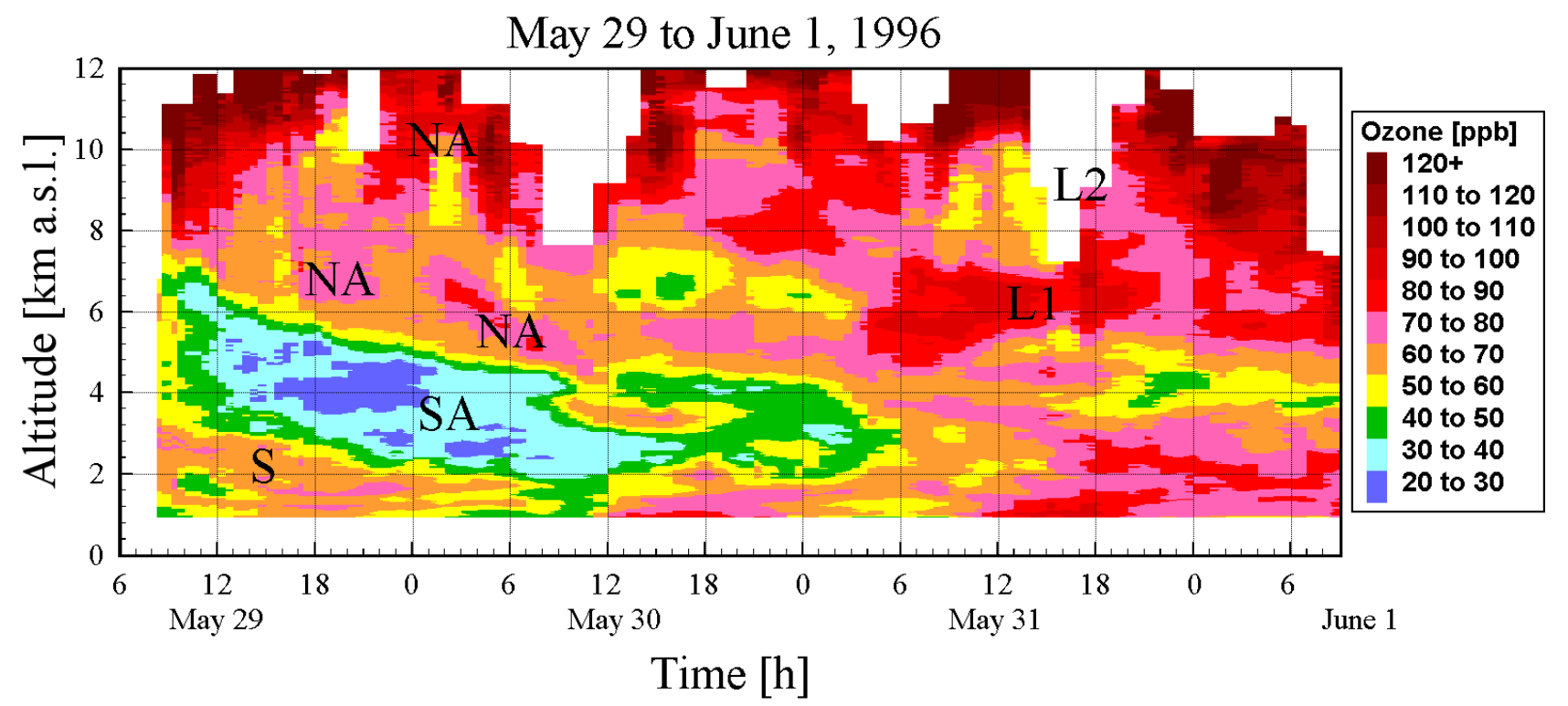

Fig. $\mathbf{S}_{\mathbf{1}}$. Colour-coded four-day lidar series of the ozone mixing ratio starting on 28 May 1996 (Eisele et al., 1999); S means stratospheric air (reaching the ground), NA air from North America and SA low-ozone air air from the subtropical Atlantic. The two layers on 31 May 1996 discussed in the paper are marked by L1 (no continental emissions) and L2 (containing emissions from North America, possibly including Mexico). The tropopause height on 31 May is $13.4 \mathrm{~km}$. 


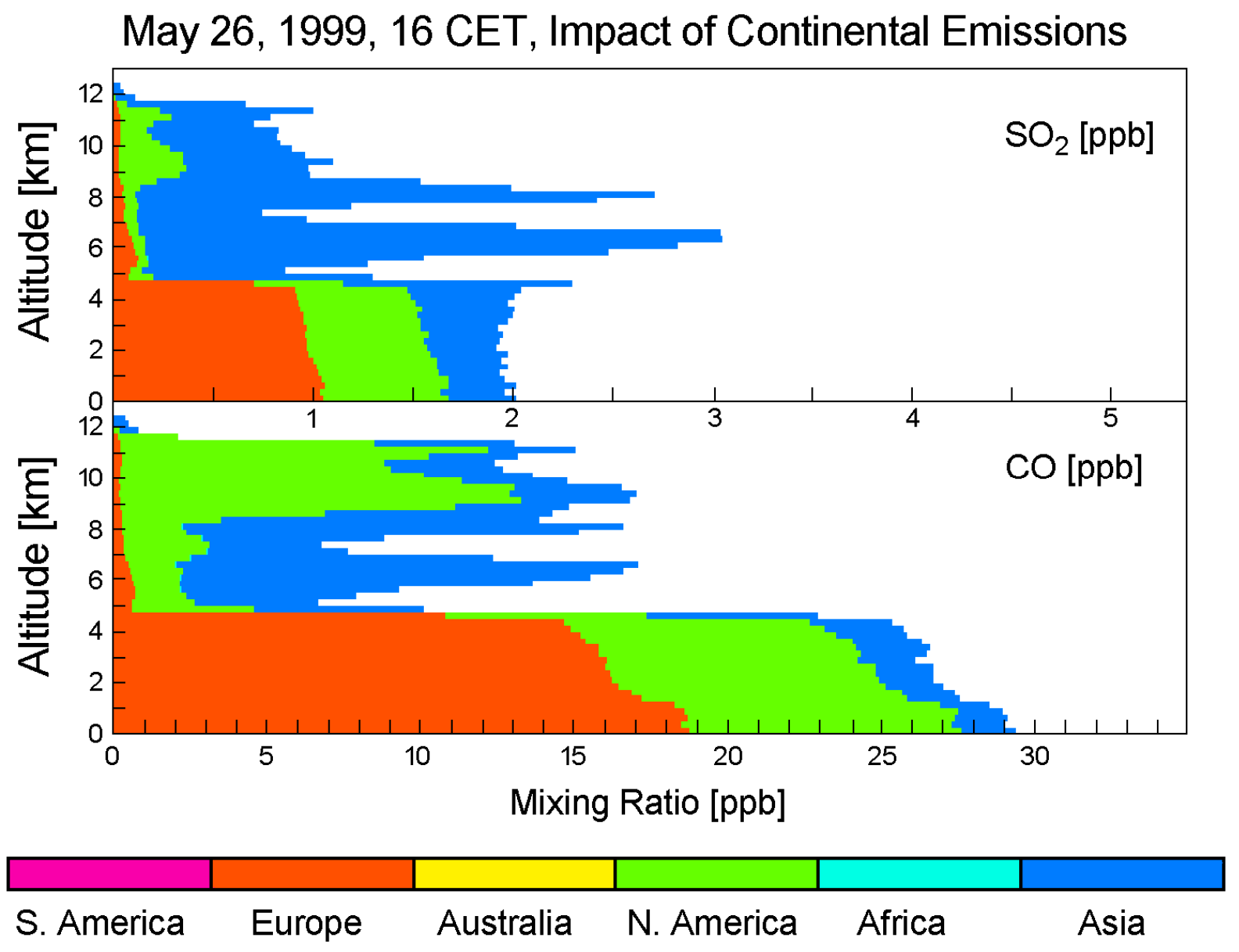

Fig. $\mathbf{S}_{2}$. Vertical distribution of $\mathrm{SO}_{2}$ and $\mathrm{CO}$ emission tracers from the different source continents, calculated for the time of the lidar measurement on 26 May 1999, shown in Fig. 8a (twenty-daysimulation); a pronounced Asian influence is demonstrated for altitudes above $5 \mathrm{~km}$. 
Jet-stream images for Case 2 (26-31 May 1999)


Fig. $\mathbf{S}_{3}$. Selected examples of the LAGRANTO visualizations of the jet streams for Case 2; the position of Garmisch-Partenkirchen is marked with a red dot next to the centre of each panel. The wind speed is colour coded. The positions where trajectories revealed STT or TST between 150 and 200 mbar are marked by green and black dots, respectively. 


\section{Humidity data for Case 5 (21-24 July 2001, Sec. 3.3)}

For this case radiosonde data from the surrounding stations Payerne, Stuttgart and Munich were inspected (Figs. S4 and S5). The situation is quite complicated due to the strongly altitude- and time-dependent wind direction (see Fig. 16 and 17 of the paper). For the layer around label L1 Payerne is the most adequate station due to westerly advection and, indeed, shows a minimum relative humidity of less than $20 \%$ between 5 and $7.5 \mathrm{~km}$. For the higher altitudes Stuttgart (northwest) is the better choice during the early phase due to north-westerly advection, with relative humidity values between 10 and $20 \%$ in almost the entire troposphere above $5.6 \mathrm{~km}$.

Close to the L3 period relative humidity values down to $11 \%$ are seen in the Stuttgart above $8 \mathrm{~km}$, presumably because of an advection parallel to that above Garmisch-Partenkirchen.
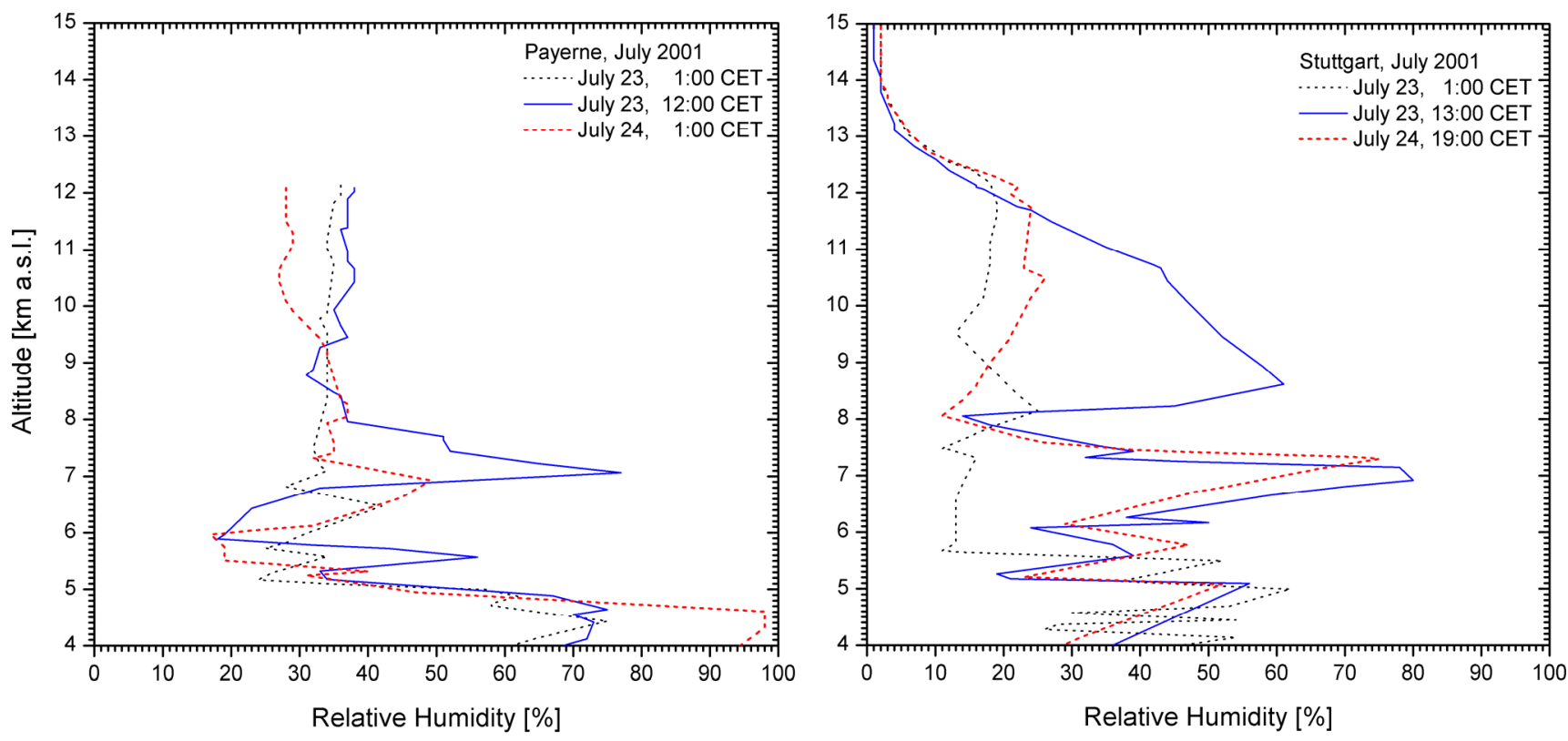

Fig S. Relative-humidity profiles for 23 and 24 July 2001; left panel; Payerne (Switzerland), about $750 \mathrm{~km}$ west (azimuth: $250^{\circ}$ ) of Garmisch-Partenkirchen; right panel: Stuttgart (Germany), about $170 \mathrm{~km}$ north-west of Garmisch-Partenkirchen. 